\title{
Florid CD4+, CD56+ T-Cell Infiltrate Associated with Herpes Simplex Infection Simulating Nasal NK-/T-Cell Lymphoma
}

Lekidelu Taddesse-Heath, M.D., Jeffery I. Feldman, M.D., Gary A. Fahle, Steven H. Fischer, Ph.D., Lynn Sorbara, Ph.D., Mark Raffeld, M.D., Elaine S. Jaffe, M.D.

Laboratory of Pathology (LT-H, LS, MR, ESJ), Hematopathology Section, National Cancer Institute, and Microbiology Service (GAF, SHF), Department of Laboratory Medicine, Warren G. Magnuson Clinical Center, National Institutes of Health, Bethesda, Maryland; and The Westerly Hospital (JIF), Westerly, Rhode Island

We report a case of Herpes simplex virus (HSV) infection of the nasopharynx associated with a dense CD4+, CD56+ T-cell infiltrate that simulated lymphoma on clinical, histologic, and immunophenotypic grounds. Histologic examination showed a tumorlike lymphoid infiltrate with extensive necrosis. Multinucleated giant cells with "ground-glass" nuclei characteristic of HSV were observed in necrotic areas but were not prominent. Immunohistochemical studies of the lymphoid infiltrate revealed a predominance of $\mathrm{T}$ cells, positive for $\mathrm{CD3}$, CD4, CD5, and CD56. Immunohistochemical staining with HSV antibody was focally positive in the multinucleated giant cells. Molecular studies using PCR and Southern blot were positive for HSV Type II. PCR studies for T-cell receptor gamma and immunoglobulin heavy chain gene rearrangements showed no evidence of a clonal population. In situ hybridization studies for Epstein-Barr virus (EBV) were negative. The clinical presentation of a large fungating mass, the extent of the lymphoid infiltrate, and the expression of CD56 all raised the possibility of a nasal NK/T cell lymphoma. However, the presence of HSV, lack of angioinvasion and angiodestruction, absence of EBV, and polyclonal $T$-cell nature of the infiltrate argued against this diagnosis. Although prior studies have not fully characterized the immunophenotypic features of the lymphocyte response to HSV in infected tissues,

Copyright $\odot 2003$ by The United States and Canadian Academy of Pathology, Inc.

VOL. 16, NO. 2, P. 166, 2003 Printed in the U.S.A.

Date of acceptance: November 15, 2002.

Address reprint requests to: Elaine S. Jaffe, M.D., Laboratory of Pathology,

National Cancer Institute/National Institutes of Health, Building 10,

Room 2N202, 10 Center Drive MSC-1500, Bethesda, MD 20892-1500; fax:

301-402-2415; e-mail: ejaffe@mail.nih.gov.

DOI: 10.1097/01.MP.0000051680.14007.D7 we postulate that the $\mathrm{CD} 56+, \mathrm{CD} 4+\mathrm{T}$-cell reaction represents a florid antiviral immune response.

KEY WORDS: Atypical lymphoid infiltrate, CD56, Herpes simplex virus, T/NK cell lymphoma.

Mod Pathol 2003;16(2):166-172

Herpes simplex virus Type I (HSV I) and Type II (HSV II) both can cause acute pharyngitis characterized by vesicles and shallow ulcers (1). Infections of the pharynx usually result in exudative lesions of the posterior pharynx, in tonsillar pillars, or both (2). Chronic herpetic lesions can occur in immunocompromised patients and are characterized by progressively large, shallow, painful ulcers (1). However, large tumorlike mass lesions causing nasopharyngeal obstruction in association with HSV have not been previously reported. We describe a patient who presented with a nasopharyngeal mass exhibiting a dense lymphoid infiltrate with extensive necrosis associated with Herpes simplex infection. The clinical and histologic features were suspicious for malignant lymphoma, and the presence of strong CD56 expression on most of the infiltrating cells further raised the possibility of lymphoma. However, further immunophenotypic and molecular studies disclosed the reactive nature of the process.

\section{CASE REPORT}

A 25-year-old female presented to her otolaryngologist physician with nasal obstruction, rhinorrhea, and persistent otitis media of 3 months duration but no symptoms of weight loss, fever, or night sweats. There was no history of underlying immunodeficiency. Physical examination revealed a large fungating cerebriform mass in the nasopharynx extending into the posterior oropharynx. There was 
no evidence of mucocutaneous lesions or significant lymphadenopathy. Laboratory findings revealed a white blood cell count of $8.9 \times 10^{9} \mathrm{~L}$, $\mathrm{Hgb}$ of $135 \mathrm{~g} / \mathrm{L}, \mathrm{HCT}$ of $41.3 \%$, and erythrocyte sedimentation rate of $35 \mathrm{~mm} /$ hours. Serologic studies for HIV and VDRL were negative, but studies were not performed for HSV. CT scan revealed a large fungating mass completely obliterating the nasopharynx and partially impinging on the oropharynx. The mass was approximately $5 \mathrm{~cm}$ in size, homogenous in enhancement with scattered areas of decreased attenuation. Because of the size of the mass, a clinical diagnosis of lymphoma was made, and the patient was referred to an oncologist. Staging for other sites of disease, including CT scan and bone marrow biopsy, were negative. Debulking with near-complete excision was performed to remove the mass and reestablish the nasopharynx, airway, and Eustachian tube patency. After excision the patient's symptoms abided, with clearing of her otitis media and rhinorrhea. The patient received no other treatment, and follow-up physical examination showed no recurrence of the lesion, except for a small adenoid-type vegetation on the roof of the nasopharynx. The patient is in apparently good health 2 years after initial presentation.

\section{MATERIALS AND METHODS}

Formalin-fixed paraffin-embedded tissue blocks and H\&E-stained slides of the nasopharyngeal biopsy were received in consultation from The Westerly Hospital, Westerly, Rhode Island.

\section{Immunohistochemistry}

Paraffin immunohistochemical stains were performed on an automated immunostainer (Ventana Medical System; Tucson, AZ), according to the manufacturer's instructions as previously described (3), using antibodies to L26 (CD20), CD3, CD8 myeloperoxidase, kappa, lambda, HSV (Dako; Carpinteria, CA), CD56, CD4, CD5 (Novocastra; Newcastle upon Tyne, United Kingdom), CD57 (Becton Dickinson; San Jose, CA), TIA-1 (Coulter; Hialeah, FL), granzyme B (Monosan, Cell Sciences, Inc.; Norwood, MA), and MIB-1 (Immunotech; Marseille, France). In situ hybridization studies for EBV early RNA (EBER-1) were performed on formalin-fixed paraffin-embedded sections as previously described (4).

\section{Molecular Studies}

\section{Immunoglobulin Heavy Chain and TCR $\gamma$ Chain Gene Rearrangement}

Formalin-fixed paraffin-embedded tissue samples were sectioned onto charged slides, deparaffinized with xylene, and hydrated through a series of ethanol: water solutions, before removal from the slides with a single-edge razor blade. The tissues were placed in $0.5-\mathrm{mL}$ PCR tubes, mixed with $20 \mu \mathrm{L}$ of Gene Releaser resin (Bioventures, Inc, Murfreesboro, TN), and layered with mineral oil. The resin-tissue mixtures were then preincubated in a PE 480 thermocycler (Perkin Elmer Cetus) according to the Gene Releaser protocol, before the addition of the specific PCR master mixes. To asses clonality, consensus primers to the joining region $(\mathrm{JH} \alpha)$ and to the conserved framework three segment of the variable region (CDR FR3) of the immunoglobulin heavy chain gene as well as consensus primers that recognize conserved sequences in the junctional region (J $\gamma 12$ and Jp12) and framework determinants of the variable region $(\mathrm{V} \gamma 101$ and $\mathrm{V} \gamma 11$ ) of the $\mathrm{T}$-cell receptor $\gamma$ chain gene were used, as previously described (5).

\section{HSV and CMV}

DNA was extracted from formalin-fixed paraffinembedded tissue using standard phenol-chloroform methods. The purified DNA was used for HSV and cytomegalovirus (CMV) assay by PCR and Southern blot. One pair of oligonucleotide primers (5'-[biotin]-TGC TTG AAG CGG TCG GCG GCG-3' and 5'-GGA CGA CCA CGA GAC CGA CAT GG-3') for HSV-1 and HSV-2 producing a 288-bp product from HSV glycoprotein B gene from either virus was used. Oligonucleotide primers (5'-[biotin]-CGC TCG CTG CTC TGC GTC CAG ACG GG-3' and 5'CCG CCG ACG GGA CCA CCG TGA CG-3') producing a 209-bp product from CMV glycoprotein B gene were used. To assess for the presence of PCR inhibition, an internal control (IC) for HSV and CMV were constructed as described previously (6) and included in each reaction, which allowed coamplification of both the IC and the targeted viral DNA with the virus-specific primer pair. The length of the IC product was $40 \mathrm{bp}$ longer than the target product to avoid preferential amplification of the IC. For each amplification reaction, a $10-\mu \mathrm{L}$ aliquot of the extracted sample was amplified in a total reaction volume of $25 \mu \mathrm{L}$. HSV or CMV primers (Midland Certified Reagent Co., Midland, TX) were added to obtain a final concentration of $0.5 \mu \mathrm{M}$, and 200 copies of either the HSV-specific or CMVspecific IC was added to each appropriate reaction. In addition, isopsoralen compound 10 (IP-10; Cerus Corp., Concord, CA) was added at a final concentration of $25 \mu \mathrm{g} / \mathrm{mL}$ to prevent amplicon carryover contamination (7). The reaction tubes were incubated in a thermal cycler (GeneAmp PCR System 9600; Perkin-Elmer Corp., Norwalk, CT) and after an initial denaturation period of 5 minutes at $94^{\circ} \mathrm{C}$, a two-step program-consisting of $94^{\circ} \mathrm{C}$ for $30 \mathrm{~s}$ and $72^{\circ} \mathrm{C}$ for 2 minutes for a total of 38 cycles and concluding with a final extension period of $5 \mathrm{~min}$ - 
utes at $72^{\circ} \mathrm{C}$-was used for both the HSV and CMV amplification.

\section{Detection of HSV PCR Products}

HSV-1- and HSV-2-specific oligonucleotide probes [HSV-1: 5'-[eu]-TGA AAC CGG CCA ACG CCG CGA-3', HSV-2: 5'[eu]-TCA AGC CGG CGA AGG TCG CCA-3' (Midland Certified Reagent Co.)] were labeled with digoxigenin (DIG)-11-dUTP by using the digoxigenin oligonucleotide tailing kit (Boehringer Mannheim, Meylan, France) according to the manufacturer's instructions. A $5-\mu \mathrm{L}$ aliquot from each PCR reaction was electrophoresed on a $2 \%$ agarose gel containing $0.1 \mu \mathrm{g}$ of ethidium bromide per $\mathrm{mL}$, and bands were visualized by UV transillumination. Amplified DNA was then transferred from the agarose gel to a positively charged nylon membrane (Hybond$\mathrm{N}+$; Amersham Life Science, Les Ulis, France) by the method of Southern (8). Using the DIG wash and block buffer set (Boehringer Mannheim), the membrane was prehybridized for 1 hour at $50^{\circ} \mathrm{C}$ in hybridization buffer containing $5 \times$ SSC, $0.1 \%$ (wt/vol) $N$-lauroylsarcosine, $0.02 \%(\mathrm{w} / \mathrm{v})$ sodium dodecyl sulfate (SDS), $0.1 \mathrm{mg}$ poly(A) solution per $\mathrm{mL}$, and $1 \%$ concentration of the blocking solution. Hybridization was performed at $50^{\circ} \mathrm{C}$ for 2 hours in the same buffer, with $1 \mathrm{pmol} / \mathrm{mL}$ of HSV-2-specific DIG-labeled probe. The membrane was washed twice, for 5 minutes each time, in $2 \times$ SSC with $0.1 \%$ SDS at $50^{\circ} \mathrm{C}$ and twice, for 5 minutes each time, in $0.1 \times$ SSC with $0.1 \%$ SDS at $50^{\circ} \mathrm{C}$. After rinsing briefly in $1 \times$ washing buffer, the membrane was incubated for 30 minutes in $1 \times$ maleic acid buffer with a $1 \%$ concentration of the blocking solution and then washed twice, for 15 minutes each time, in $1 \times$ washing buffer. Bound DIG-labeled probe was detected by using a digoxigenin luminescent detection kit (Boehringer Mannheim) according to the manufacturer's instructions. An autoradiograph of the mem- brane was produced, using it to expose X-Omat AR film (Eastman Kodak Co., Rochester, NY) for 10 to 30 minutes. The DIG-labeled HSV-2-specific probe was then stripped from the membrane by washing twice, for 10 minutes each time, in $0.4 \mathrm{~N}$ $\mathrm{NaOH}$ with $0.1 \%$ SDS and then rinsing in $2 \times$ SSC. The HSV-1-specific DIG-labeled probe was then hybridized to the membrane and an autoradiograph made as stated above.

\section{RESULTS}

\section{Histology and Immunohistochemistry}

Sections of the nasopharyngeal biopsy revealed an extensive, dense lymphoid infiltrate with infiltration of submucosal glands. The lymphoid cells were uniform, predominantly composed of small lymphocytes with few scattered plasma cells and histiocytes. The majority of the lymphocytes were small in size, had scant cytoplasm and round nuclear contours with clumped chromatin, and did not show significant cytological atypia (Fig. 1B). Occasional larger atypical cells with prominent nucleoli were present but were not conspicuous, and mitotic figures were rare to absent. Germinal centers were not identified. There were extensive areas of zonal necrosis. However, vascular invasion and destruction and granulomas were not observed. Within the areas of necrosis, multinucleated giant cells with "ground-glass" nuclei characteristic of Herpes simplex viral intranuclear inclusions were noted (Fig. 1A). Immunohistochemical stain using antibody to HSV was focally positive in the multinucleated giant cells within the necrotic areas (Fig. 2B). Immunohistochemical analysis showed the lymphoid cells to be predominantly $\mathrm{T}$ cells, positive for CD3, CD5, and CD56. CD4-positive cells exceeded CD8-positive cells (Fig. 2C-F). The infiltrates showed a high proliferative rate demonstrated by MIB-1 staining ( $>75 \%$ of the cells posi-
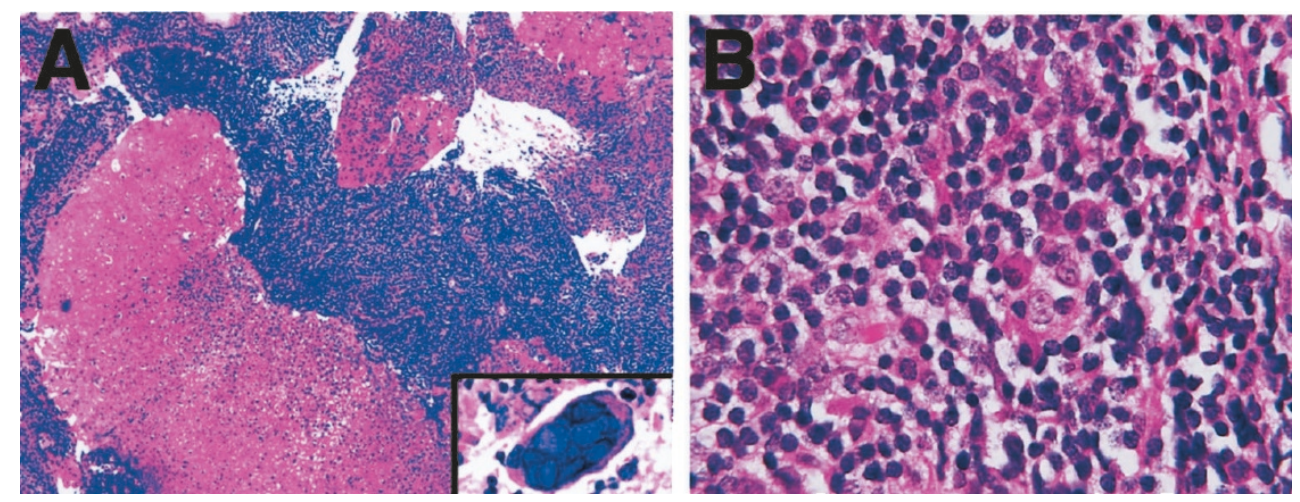

FIGURE 1. Histologic section of the nasopharyngeal mass. There are extensive areas of zonal necrosis focally showing multinucleated giant cells with ground-glass nuclei (inset) characteristic of HSV infection (A). Dense lymphoid infiltrates were present, composed of a uniform population of small lymphocytes with admixed plasma cells (B). 

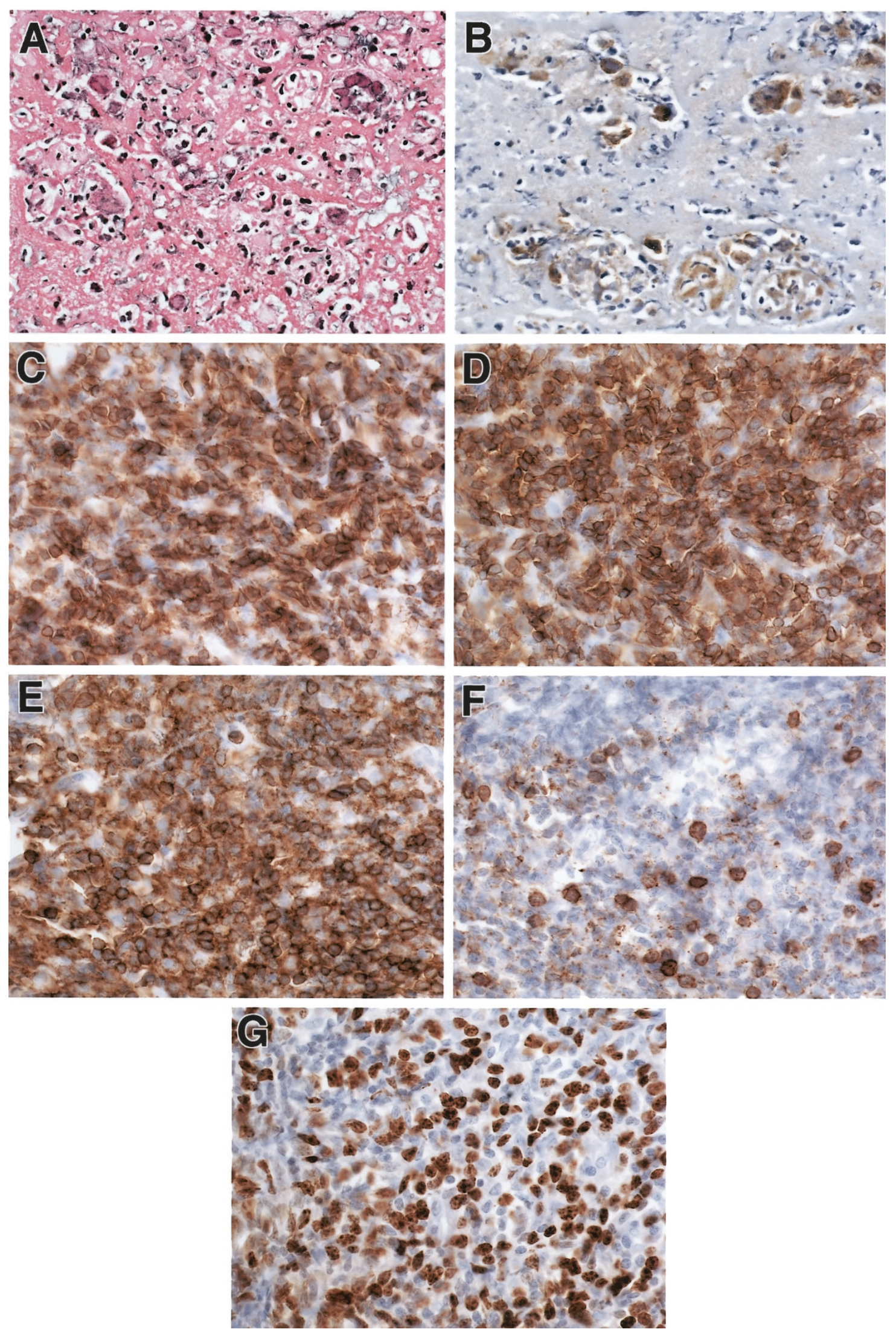

FIGURE 2. Immunohistochemical studies of the nasopharyngeal mass. Histologic section of the necrotic area (A) and corresponding immunohistochemical stain with HSV antibody showing positive nuclear staining (B). The lymphoid infiltrates were predominantly T cells positive for CD3 (C) and CD56 (D), with a predominance of CD4- (E) over CD8-positive cells (F). G, High proliferative rate with MIB-1 staining. 
tive; Fig. 2G). There were scattered TIA-1-positive and granzyme B-positive cells, whereas stains for CD57 and myeloperoxidase were negative. Admixed CD20 (L26)-positive B cells were present.

\section{Molecular and In Situ Hybridization Studies}

PCR studies for immunoglobulin heavy chain gene and $\mathrm{T}$-cell receptor gamma gene rearrangements did not reveal a clonal $\mathrm{T}$ or B-cell population (data not shown). Agarose gel electrophoresis of PCR amplification for HSV and CMV are shown in Figure 3A. The patient's sample was positive for the 288-bp HSV amplification product (Lanes 6-7). This amplified DNA gave a strong signal with the
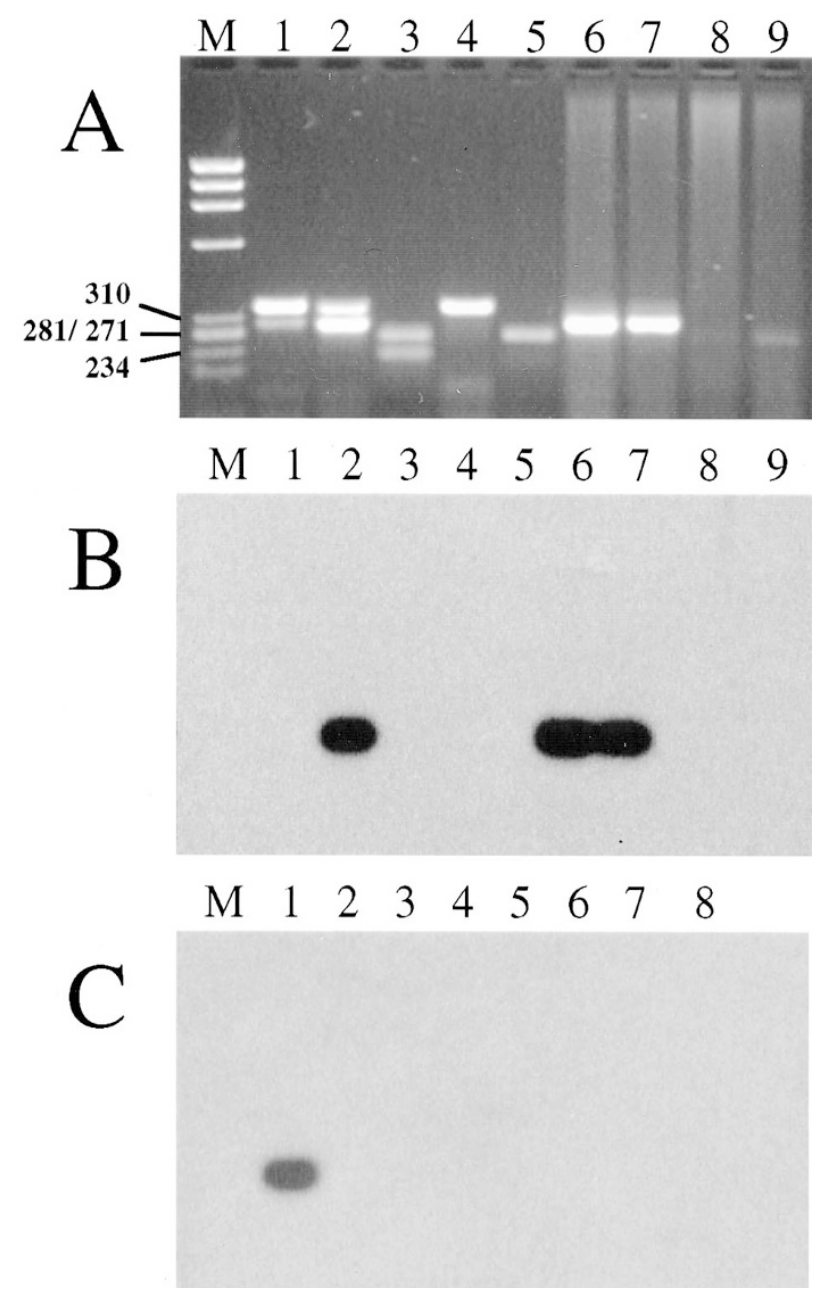

FIGURE 3. A, ethidium bromide-stained $2 \%$ agarose gel of HSV and CMV amplification reaction. Lane $\boldsymbol{M}$, HaeIII-digested $\phi$ X174 DNA (molecular weight markers); Lanes 1 and 2, HSV PCR-positive control (288 bp) and HSV internal control (IC; 332 bp); Lane 3, CMV PCRpositive control (209 bp) and CMV IC (249 bp); Lane 4, HSV-negative control with HSV IC (332 bp); Lane 5, CMV-negative control with CMV IC (249 bp); Lanes 6-7, HSV PCR with HSV IC on extracted DNA from the nasopharyngeal mass; Lanes 8-9, CMV PCR with CMV IC on extracted DNA from the nasopharyngeal mass. B, Southern blot of the agarose gel hybridized with DIG-labeled HSV-2 probe. Lane 2, positive control. Lanes 6, 7, nasopharyngeal mass. C, Southern blot of the agarose gel stripped and rehybridized with DIG-labeled HSV-1 probe. Lane 1, positive control. Lanes 6, 7, nasopharyngeal mass.
DIG-labeled HSV-2 probe (Fig. 3B; Lanes 6-7) and no signal for the DIG-labeled HSV-1 probe (Fig. 3C; Lanes 6-7). The patient's sample was negative for the 209-bp CMV amplification product, and only the 249-bp IC product amplified (Fig. 3A; Lanes 8-9). These results confirmed the presence of only HSV-2 DNA in the extracted patient sample. In situ hybridization for Epstein-Barr virus was negative, with an adequate U6 control for RNA integrity.

\section{DISCUSSION}

HSV infection can cause ulcerations and extensive necrosis of oropharynx (9) and tonsil (10). However, the clinical presentation of a large obstructive nasopharyngeal mass associated with HSV infection has not been previously described. In a report of six patients with Herpes zoster polyneuritis of the head and neck, three patients were reported to have clinical and radiographic evidence of mass in the nasopharyngeal region (11). Although biopsies were reported to have ruled out malignancies, there was no detailed clinicopathologic description of the mass, except in one patient, in whom a right parapharyngeal mass with microscopic findings of nonspecific lymphocytic infiltration of submucosal tissue was reported.

In the current case, the size and obstructive nature of the mass led to a clinical impression of lymphoma, and the preliminary pathologic diagnosis was lymphoma. Histologically, the lesion was worrisome because of the extensive tissue necrosis and dense lymphoid infiltrate. Immunohistochemical and molecular studies were performed and showed a predominantly T-cell population, CD3+, $\mathrm{CD} 5+, \mathrm{CD} 4+$, and CD56+, with a brisk proliferative rate raising the differential diagnosis of extranodal NK/T cell lymphoma, nasal type. Although the lymphocytes were positive for CD56, angioinvasion and angiodestruction were not observed. In addition, the cells appeared to have a T-cell, rather than NK-cell, phenotype, expressing CD4 and CD5 in addition to CD3. Finally, the absence of EBV argued against a diagnosis of extranodal NK/T cell lymphoma. CD56 positivity also has been reported in T-cell lymphomas, most commonly of gamma delta T-cell origin $(12,13)$. However, in this patient, PCR studies for clonal T-cell receptor rearrangement were negative and follow-up at 2 years after initial biopsy showed no evidence of recurrence.

The observation of multinucleated cells with intranuclear inclusions in the setting of extensive necrosis led to a suspicion of HSV infection. Subsequent studies for HSV, including immunohistochemistry and PCR, confirmed the presence of HSV in the multinucleated giant cells. The extensive necrotizing inflammation associated with 
Herpes simplex Type II and lack of clonal T-cell receptor gene rearrangement point toward a reactive T-cell proliferation rather than peripheral T-cell lymphoma.

CD56 is an adhesion molecule that is expressed on cells of the central nervous system, most NK cells, as well as a subpopulation of cytotoxic T-cells (12) and has neither disease nor lineage specificity (13). The distribution of CD56-positive cells appeared to coincide with staining for CD3 and CD4, although double staining was not performed. The co-expression of CD3, CD4, CD5, and CD56 favors a $\mathrm{T}$-cell rather than NK-cell derivation for these cells. Only a small proportion of CD4+ CD56+ cytotoxic $\mathrm{T}$ cells can be detected in peripheral blood, although they have been noted with greater frequency in the liver (14). In addition, patients chronically infected with hepatitis B virus (HBV) were found to have an intrahepatic accumulation of $\mathrm{CD} 4+\mathrm{CD} 56+\mathrm{T}$ cells that were not detected in the peripheral blood of the same patients. This observation suggests that viral infections including $\mathrm{HBV}$ and HSV may promote the expansion of CD4+, CD56+ $\mathrm{T}$ cells in the target organ (15).

Cell-mediated immunity by $\mathrm{CD} 4+\mathrm{T}$ cells that recognize HSV has been shown to be important in the resolution of primary HSV infection (16). The predominance of a CD4+ T-cell response has been related to the capacity of the virus to down-regulate MHC Class I expression to escape CD8+ T-cell surveillance (17). In addition, the responding CD4+ $\mathrm{T}$-cells can function as cytotoxic $\mathrm{T}$ cells, using the granule exocytosis pathway common to NK cells (18-20). However, the expression of CD56+ on these cells has not been reported. It is of interest that both TIA-1 and granzyme B were largely negative on the infiltrating lymphoid cells. To investigate whether $\mathrm{CD} 4+, \mathrm{CD} 56+\mathrm{T}$ cells could be readily detected in acute herpetic infections, we retrospectively analyzed one liver and two skin biopsies. However, these lesions showed mostly necrosis with only a scant lymphoid infiltrate and were negative for $\mathrm{CD} 4+$, CD56+ cells. A prior report documented the predominance of a CD4+ T-cell response in the early stages of herpes infection in the skin, but immunohistochemical studies for CD56 were not performed (21).

The lymphoid response to HSV infection has been described most often in the context of herpetic lymphadenitis (22-28). In addition, herpetic lymphadenitis is more commonly seen in patients with compromised immunity (27-28). Although these reports describe the histopathologic findings in lymph nodes, detailed immunohistochemical studies have not been performed. In addition, lymphoid proliferations of tumor-like proportions are rare. The protracted, 3-month duration of the herpetic infection in our patient most likely contrib- uted to the marked CD4+, CD56+ T-cell expansion as an antiviral immune response.

Acknowledgments: We thank Cindy Harris and Mann Youn Leong Son for excellent immunohistochemical technical support.

\section{REFERENCES}

1. Hunsaker DH, Boone JL. Etiology of infectious diseases of the upper respiratory tract. In: Ballenger JS, Snow JB, editors. Otorhinolaryngology head and neck surgery. 15th ed. Philadelphia: Williams and Wilkins; 1996. p. 70-1.

2. Corey L. Herpes simplex virus. In: Mandell GL, Bennett JE, Dolin R, editors. Principles and practice of infectious diseases. 5th ed, vol 2. Philadelphia: Churchill Livingston; 2000. p.1566-7.

3. Quintanilla-Martinez L, Thieblemont C, Fend F, Kumar S, Pinyol M, Campo E, et al. Mantle cell lymphomas lack expression of p27 (Kip1), a cyclin-dependent kinase inhibitor. Am J Pathol 1998;153:175-82.

4. Kingma DW, Medeiros LJ, Barletta J, Raffeld M, Mann RB, Ambinder RF, et al. Epstein-Barr virus is frequently identified in non-Hodgkin's lymphomas associated with Hodgkin's Disease. Am J Surg Pathol 1994;18:48-61.

5. Xie XY, Sorbara L, Kreitman RJ, Fukushima PI, Kingma DW, Stetler-Stevenson M. Development of lymphoproliferative disorder of granular lymphocytes in association with hairy cell leukemia. Leuk Lymphoma 2000;37:97-104.

6. Fahle GA, Fischer SH. Comparison of six commercial DNA extraction kits for recovery of cytomegalovirus DNA from spiked human specimens. J Clin Microbiol 2000;38:3860-3.

7. Fahle GA, Gill VJ, Fischer SH. Optimal activation of isopsoralen to prevent amplicon carryover. J Clin Microbiol 1999; 37:261-2.

8. Southern EM. Detection of specific sequences among DNA fragments separated by gel electrophoresis. J Mol Biol 1975; 98:503-17.

9. Karnauchow PN, Kaul WH. Chronic herpetic laryngitis with oropharyngitis. Ann Otol Rhinol Laryngol 1988;97:286-8.

10. Wat PJ, Strickler JG, Myers JL, Nordstrom MR. Herpes simplex infection causing acute necrotizing tonsillitis. Mayo Clin Proc 1994;69:269-71.

11. Golden LI, Deeb ZE, deFries H. Atypical findings in cephalic Herpes zoster polyneuritis: case report and radiographic findings. Laryngoscope 1990;100:494-7.

12. Poggi A. Workshop VI section NK cell. In: Kishimoto T, et al., editors. Leucocyte typing VI. White cell differentiation antigens. New York: Garland Publishing Inc.; 1998. p. 1155-6.

13. Jaffe ES. Classification of natural killer cell (NK) and NK-like T-cell malignancies. Blood 1996;87:1207-10.

14. Hashimoto S, Takii Y, Iiai T, Tsuchida M, Watanabe H, Shinada S, et al. Characterization of CD56+ T-cells in humans: their abundance in the liver and similarity to extrathymic T-cells in mice. Biomed Res (Tokyo) 1995;16:1-9.

15. Barnaba V, Franco A, Paroli M, Benvenuto R, Depetrillo G, Burgio VL, et al. Selective expansion of cytotoxic T-lymphocytes with a CD4+ CD56+ surface phenotype and a T-helper Type 1 profile of cytokine secretion in the liver of patients chronically infected with Hepatitis B virus. J Immunol 1994;152:3074-87.

16. Lopez C, Arvin AM, Ashley R. Immunity to herpes virus infection in humans. In: Roizman B, Whitley RJ, Lopez C, editors. The human herpesviruses. New York: Raven Press; 1993. p. 402-3.

17. Hill AB. Mechanisms of interference with the MHC class I-restricted pathway of antigen presentation by herpesviruses. Immunol Cell Biol 1996;74(6):523-6. 
18. Yasukawa M, Yakushijin Y, Hasegawa H, Miyake M, Hitsumoto Y, Kimura S, et al. Expression of perforin and membrane-bound lymphotoxin (tumor necrosis factor-beta) in virus-specific CD4+ human cytotoxic T-cell clones. Blood 1993;81(6):1527-34.

19. Yasukawa M, Yakushijin Y, Fujita S. Two distinct mechanisms of cytotoxicity mediated by herpes simplex virusspecific CD4+ human cytotoxic T cell clones. Clin Immunol Immunopathol 1996;78(1):70-6.

20. Yasukawa M, Ohminami H, Yakushijin Y, Arai J, Hasegawa A, Ishida Y, et al. Fas-independent cytotoxicity mediated by human CD4+ CTL directed against herpes simplex virusinfected cells. J Immunol 1999;162(10):6100-6.

21. Cunningham AL, Turner RR, Miller AC, Para MF, Merigan TC. Evolution of recurrent herpes simplex lesions. An immunohistologic study. J Clin Invest 1985;75:226-33.

22. Epstein JI, Ambinder RF, Kuhajda FP, Pearlman SH, Reuter VE, Mann RB. Localized herpes simplex lymphadenitis. Am J Clin Pathol 1986;86(4):444-8.
23. Tamaru J, Mikata A, Horie $\mathrm{H}$, Itoh $\mathrm{K}$, Asai $\mathrm{T}$, Hondo R, et al. Herpes simplex lymphadenitis. Report of two cases with review of the literature. Am J Surg Pathol 1990;14(6):571-7.

24. Gaffey MJ, Ben-Ezra JM, Weiss LM. Herpes simplex lymphadenitis. Am J Clin Pathol 1991;95(5):709-14.

25. Miliauskas JR, Leong AS. Localized herpes simplex lymphadenitis: report of three cases and review of the literature. Histopathology 1991;19(4):355-60.

26. Witt MD, Torno MS, Sun N, Stein T. Herpes simplex virus lymphadenitis: case report and review of the literature. Clin Infect Dis 2002 Jan 1;34(1):1-6.

27. Higgins JP, Warnke RA. Herpes lymphadenitis in association with chronic lymphocytic leukemia. Cancer 1999;86(7): 1210-5.

28. Joseph L, Scott MA, Schichman SA, Zent CS. Localized herpes simplex lymphadenitis mimicking large-cell (Richter's) transformation of chronic lymphocytic leukemia/small lymphocytic lymphoma. Am J Hematol 2001;68(4):287-91. 